\title{
Mitos Radhin Saghârâ dalam Kajian Strukturalisme Levi-Strauss
}

\author{
Dewi Angelina \\ Jurusan Sastra Indonesia, Fakultas Ilmu Budaya, Universitas Jember \\ Kireina10zense@gmail.com
}

Diterima 2 Januari 2018/Disetujui 8 Januari 2018

\begin{abstract}
Radhin Sahgârâ is one of myth from Madurese. The myth is considered can help to understand the Madurese's culture. The culture inside Radhin Sahgârâ myth still expected sacral and belief by some of Madurese people today. The connection among myth and belief of Madurese cultural is very interesting to analysis uses Levi- Straus's structuralism theory. Levi-Straus's structuralism theory is used as an analytical model to interpret the myth of Radhin Sahgârâ. Using this theory, there are two steps to analyze the structure of the myth. The firt step, to find mytheme-mytheme in myth. In the second step, there are some figures who have an important role in the life of the community at thet time, and it influenced some Madurese beliefs today. The result of this analysis is to show the myth as one of tool that is used to understand the social culture study telling in the literature.
\end{abstract}

Keyword: myth, Madurese culture, Levi-Strauss' Structuralism.

\section{Pendahuluan}

Karya sastra sebagai salah satu hasil kebudayaan manusia menggambarkan kehidupan dan persoalan-persoalan manusia. Gambaran kehidupan di dalamnya, merupakan manifestasi ekspresi lahir batin seorang pengarang yang diperoleh dalam kehidupan nyata. Kehidupan manusia dengan kompleksitas persoalan dan kejadian sehari-hari, merupakan sumber bagi pengarang untuk memperoleh inspirasi yang akan menimbulkan ide-ide aktual sebagai aspek untuk diekspresikan guna melihat kehidupan lebih jauh lagi. Macam-macam segi kehidupan tersebut hadirnya sebuah cerita mengenai peristiwa-peristiwa yang dianggap mempunyai makna dan tingkat penalaran yang kuat disebut sebagai mitos. Awal yang cukup sederhana dari kisah rakyat berlatarkan kehidupan istana centris, rakyat jelata dan dunia gaib diperkenalkan oleh sastra lisan. Hal tersebut tidak berhenti menjadi cerita rakyat saja, para penikmat cerita merangkum cerita rakyat menjadi sastra tulis, sehingga dapat dibaca oleh generasi berikutnya.

Logika dasar atau nalar manusia menurut Levi-Strauss, mestinya terwujud dalam berbagai aktivitas kehidupan sehari-hari manusia. Nalar ini memang mengikuti struktur tertentu dalam bekerjanya, kita perlu menganalisis berbagai aktivitas yang merupakan perwujudan dari nalar tersebut. Fenomena-fenomena budaya pada dasarnya merupakan perwujudan dari nalar tersebut. Akan tetapi, tidak semua fenomena sama mudahnya untuk dibedah. Perlu dicari fenomena budaya yang sesuai, dan itu adalah mitos (AhimsaPutra,2009:75-76). 
Mitos dalam pandangan Levi-Strauss tidak harus dipertentangkan dengan sejarah atau kenyataan, karena perbedaan makna dari dua konsep ini terasa semakin sulit dipertahankan dewasa ini. Mitos dalam konteks strukturalisme Levi-Strauss tidak lain adalah dongeng. Dongeng merupakan sebuah kisah atau cerita yang lahir dari hasil imajinasi manusia, dari khayalan manusia, walaupun unsur-unsur khayalan tersebut berasal dari apa yang ada dalam kehidupan manusia sehari-hari. Salah satu yang menarik bagi Levi-Strauss adalah kenyataan bahwa nalar manusia tersebut mendapatkan tempat ekspresinya yang paling bebas dalam dongeng. Dongeng-dongeng seringkali ditemukan mirip atau agak mirip satu dengan yang lain (Ahimsa-Putra,2009:75-76).

Mitos-mitos yang sering dijadikan sebagai kajian oleh Levi-Strauss perlambangan dari bentuk kebudayaan dan antropologi sebagaian bangsa tidak hanya terdapat di wilayah Eropa saja. Akan tetapi, mitos yang tercipta di Indonesia juga dapat dikaji berdasarkan teori struktural Levi-Strauss. Jajaran pulau di seluruh Indonesia telah menghadirkan kemajemukan cerita rakyat, dongeng dan mitos. Objek tesebut akan menggambarkan kebudayaan dan sistem-sistem yang terdapat dalam bagian kajian antropologi budaya. Salah satu mitos yang menarik menurut peneliti adalah mitos dari Madura dengan menggunakan bahasa Madura sebagai media penyampaian cerita. A.Sulaiman Sadik yang aktif di Yayasan Pakem Maddu Pamekasan juga sebagai dosen Universitas Madura telah berhasil mengumpulkan cerita rakyat dalam bukunya, 'Sangkolan'. Hal tersebut menggugah peneliti untuk mengamati lebih dalam lagi mengenai mitos yang berjudul 'Radhin Saghârâ' dengan menggunakan kajian struktural Levi-Strauss. Pembahasan lebih lanjut mengenai mitos tersebut peneliti susun dalam sebuah artikel yang berjudul' Mitos Radhin Saghârâ dalam Kajian Struktural LeviStrauss.

\section{Metode}

Claude Levi-Strauss adalah ahli antropologi berkebangsaan Prancis. Di masa mudanya dia lebih banyak membaca buku-buku hukum dan filsafat karena pada tahun 1927 Levi-Strauss masuk Fakultas Hukum Paris dan pada saat yang sama juga belajar filsafat di Universitas Sorbonne. Levi-Strauss mengikuti persiapan untuk ujian agregation dalam filsafat, yang merupakan salah satu gelar tertinggi di Prancis. Paradigma strukturalisme yang dirintis oleh Levi-Strauss diaplikasikan ke berbagai karya-karya monumental Levi-Strauss berupa tertalogi, mengenai mitos-mitos orang indian di benua Amerika yang dianalisis struktural.

Karya-karyanya cenderung menunjukkan perspektif untuk memahami berbagai kebudayaan suku bangsa di dunia yang begitu bervariasi. Levi-Strauss sebagai pelopor strukturalisme dalam antropologi tidak hanya pendapat tempat yang sangat terhormat dalam dunia antropologi, tetapi juga dalam dunia cabang ilmu pengetahuan yang lain seperti sastra, sosiologi, filsafat, dan telaah seni. Keteguhan dan keyakinannya akan manfaat pendekatan struktural bagi fenomena sosial budaya telah membangkitkan kekaguman dan penghargaan dari para ilmuan sosial dan budaya di dunia Barat. 
Buku-buku dan artikel yang ditulisnya merupakan karya-karya ilmiah yang boleh dikatakan paling banyak dikutip oleh ahli-ahli antropologi pada tahun-tahun 1970-an dan 1980-an (Ahimsa-Putra,2009:3).

1. Pemikiran-pemikiran Levi-Strauss yang begitu menarik dan berpengaruh tersebut ternyata tidak mudah dipahami oleh para ilmuwan sosial budaya di Indonesia. Ada beberapa faktor penyebab di sini :

a) Paradigma struktural Levi-Strauss banyak diilhami oleh linguistik (disiplin ilmu yang tidak begitu populer di kalangan pakar sosial budaya Indonesia)

b) Paradigma struktural Levi-Strauss juga merupakan sebuah epistemologi positivistik yang dianut oleh sebagian besar ilmuwan sosial budaya Indonesia.

2. Mitos dan Bahasa

Levi-Strauss berpendapat bahwa sebagian ahli bahasa dan ahli antropologi memandang fenomena bahasa dan kebudayaan dari perspektif yang kurang tepat karena mereka menganggap ada hubungan kausalitas antara dua fenomena tersebut. Perspektif yang lebih tepat menurutnya adalah memandang bahasa dan kebudayaan sebagai hasil dari aneka aktivitas yang pada dasarnya sama atau mirip.

Analisis-analisis yang dilakukan oleh para ahli bahasa atas berbagai macam bahasa di dunia sangat didukung oleh Levi-Strauss. Oleh karena itu, Levi- Strauss menganggap perlunya para ahli antropologi memahami yang telah dilakukan oleh ahliahli linguistik dalam kajian-kajian mereka mengenai fenomena kebahasaan. Hal tersebut harus didukung karena menurut Levi-Strauss pendekatan baru linguistik penting tidak hanya bagi linguistik saja, tetapi juga bagi disiplin ilmu lainnya. Strukturalisme LeviStrauss secara implisit menganggap teks naratif, seperti misalnya mitos, sejajar dengan kalimat berdasarkan dua hal, yaitu : teks tersebut adalah satu kesatuan yang bermakna dan teks tersebut memberikan bukti bahwa dia diartikulasikan oleh bagian-bagian.

3. Mitos dan Musik

Levi-Strauss juga melihat persamaan mitos dengan musik. Mitos maupun musik bekerja melalui penyesuaian dua jenis kisi: kisi internal dan kisi eksternal. Perbedaannya adalah bahwa pada musik kisi-kisi yang tidak sederhana ini menjadi bertambah rumit dan hampir mencapai reduplikasi. Pendapat Levi-Strauss selanjutnya adalah bahwa mitos dan musik pada dasarnya adalah bahasa. Mitos seperti halnya musik, bekerja di atas sebuah kontinum dengan dua aspek. Aspek eksternal kontinum, berupa berbagai peristiwa sejarah yang dianggap bersejarah. Aspek internal yang meliputi periodisitas dari gelombang-gelombang yang ada di pikiran manusia.

Mitos menurut Levi-Strauss adalah suatu gejala kebahasaan yang berbeda dengan gejala kebahasaan yang dipelajari oleh ahli linguistik. Mitos sebagai bahasa dengan demikian memiliki tata bahasanya sendiri dan Levi-Strauss tampaknya berupaya untuk mengungkapkan tata bahasa ini dengan menganalisis unsur terkecil datri bahasa mitos, yakni mytheme (miteme). Miteme adalah unsur-unsur dalam konstruksi wacana mitis, yang juga merupakan satuan-satuan yang bersifat kosokbali, relatif, dan negatif. (Ahimsa-Putra,2009:102). Unit-unit yang dinamakan mytheme merupakan unit terkecil dari cerita. Mytheme dapat menjadi sebuah perantara makna dari cerita yang umumnya berisi tentang tindakan dan peristiwa oleh tokoh-tokoh dalam cerita. Makna yang 
diperoleh dari miteme tersebut dapat berupa sebuah tanda yang mempunyai nilai dalam konteks tertentu. Konteks yang bermakna dalam miteme dapat dinilai dari segi latar belakang kehidupan sosial, hubungan sosial, dan nilai-nilai kebudayaan. Nilai bermakna miteme dapat memunculkan tokoh-tokoh penting dalam mitos yang akhirnya mempunyai kedudukan sacral, penting, dihormati serta diyakini keberadaannya oleh masyarakat pemilik mitos.

\section{Pembahasan}

\subsection{Sinopsis Mitos Radhin Saghârâ}

Di pulau jawa ada raja yang bernama Sang Yang Tunggal. Raja baru saja memiliki dua putra, laki-laki dan perempuan. Putranya bernama Sang Yang Sumba, putrinya bernama Bendoro Ghung. Di suatu waktu raja sangat murka karena putrinya diketahui hamil, kemurkaannya disebabkan karena putrinya belum bersuami. Rasa sedihnya membuat raja menyuruh patihnya yang bernama Prang Gulang membawa putrinya ke hutan serta disuruh penggal lehernya, dan kepalanya dianjurkan untuk dibawa pulang ke keraton sebagai bukti bahwa putrinya telah mati.

Raja memerintakan Patih Prang Gulang segera membawa Putri Bendara. Sang putri rupanya sudah merasa bahwa dirinya akan dibunuh oleh ayahandanya. Setelah keluar dari kraton hingga setibanya di hutan sang putri tidak henti-hentinya menangis iba, hingga matanya sembab. Patih Prang Gulang adalah seorang patih yang baik, sehingga tidak tega memenggal kepala Putri Bedara Ghung. Sesampainya di hutan Patih Prang Gulang hanya bisa duduk termangu melihat ke tanah. Di dekat patih, Sang Putri tetap menangis sesenggukan kemudian Sang Putri sadar bahwa manusia hidup pasti akan mati. Dia pasrah dan menyuruh Patih Prang Gulang untuk segera memenggal kepalanya. Akan tetapi, permintaan Sang Putri tidak dikabulkan oleh Patih karena dia tidak tega untuk membunuh wanita yang sedang mengandung.

Patih Prang Gulang kemudian membawa Sang Putri keluar dari hutan dan segera menuju pinggir pesisir. Setibanya di pinggir pesisir, Patih Prang Gulang segera menebang pohon, kemudian dibuatnya rakit. Setelah rakit yang dibuatnya selesai, didorong ke pinggir pantai dan Sang Putri diperintahkan naik ke atas rakit. Patih menyuruh Sang Putri segera berlayar hingga akhirnya menemukan sebuah daratan. Pesan patih, jika nanti bayinya lahir dianjurkan diberi nama Radhin Saghârâ. Patih Prang Gulung juga menyuruh supaya Putri berteduh di bawah pohon besar hingga akhirnya penduduk sekitar menghampirinya. Sang Putri hanya bisa diam dan mengangguk tanda mengerti dengan pesan Patihnya. Pesan terakhir patih bahwa dia tidak akan kembali ke keraton dan kemudian mendorong rakit yang dinaiki oleh Sang Putri menuju tengah laut. Beriringan dengan lambaian tangannya Patih bersiul seolah-olah memanggil sesuatu dengan sebuah isyarat. Tidak lama, lima ekor lumba-lumba datang dari tangah samudra.

Lmba-lumba itu mengangguk-angguk seolah-olah mengerti isyarat patih untuk mendorong rakit yang dinaiki Sang Putri, serta menjaganya dari mara bahaya. Di saat berada di tengah samudra, Sang Putri melahirkan putranya. Proses persalinannya membuat Sang Putri kelulahan sehingga ia tertidur dan rakitnya pun melabuh di sudut daratan. Lumba-lumba yang sedari kamarin-kemarin setia menjaga Sang Putri dan 
putranya, tiba-tiba berteriak-teriak membangunkan majikannya itu. Suara lumba-lumba yang keras membangunkan Sang Putri dari tidurnya dan ia segera menggendong Radhin Saghârâ untuk berteduh di bawah pohon besar. Selang beberapa menit datanglah penduduk setempat menghampiri Sang Putri dan mengajaknya ke rumah mereka. Mereka merasa kagum melihat Raden Samudra yang baru saja dilahirkan, tetapi sudah seperti anak yang berumur satu tahun.

Keadaan menjadi semakin harmonis layaknya keluarga yang telah lama tidak bertemu. Desa yang telah menjadi tempat tinggal baru Sang Putri konon adalah desa Gheggher. Pada zaman dahulu pulau tersebut layaknya berada di atas gunung, tetapi sekarang daratan sudah mulai lebar, laut semakin jauh dari daerah itu. Dahulu, daratan itu menyatu dengan daratan sebelah selatan (pulau Jawa), tetapi karena terjadi gempa dan gunung meletus sebagian daratan tertutup air laut. Kedatangan putra istimewa Sang Putri, yang akhirnya menjadikan pulau tersebut diberi nama Madura, yaitu Madunya Segara (samudra).

Radhin Saghârâ akhirnya tumbuh dewasa dan menjadi raja di pulau Madura. Di suatu malam dia bermimpi, melihat Patih Prang Gulang berperang dengan Jhuko' Rajhâmèna. Perang tersebut berakhir dengan tewasnya Jhuko' Rajhâmèna. Tombak yang ditancapkan Patih Prang Gulang di bagian perut dan kepala. Seakan-akan nyata dalam mimpi itu terjadi badai yang sangat dasyat, pohon-pohon besar tumbang dan air laut meluap-luap. Sewaktu Radhin Saghârâ terbangun dari mimpinya dia merasa senang karena yang dilihatnya hanya mimpi. Selang berapa waktu ada orang dari keraton datang dengan terengah-engah, memberitahukan bahwa ada mayat yang tidak dikenal ada halaman keraton. Di bagian kepala dan perutnya tertancap tombak.

Radhin Saghârâ memerintahkan pengawalnya untuk mencabut tombak itu dan membawa ke hadapannya. Akan tetapi, seluruh pengawal kerajaan dan para pendekar di pulau itu tidak ada yang mampu mencabut tombak. Radhin Saghârâ akhirnya turun tangan. Rakyatnya terkagum-kagum melihat Radhin Saghârâ dengan mudah mencabut tombak yang tertancap pada mayat tersebut. Anehnya lagi, kedua tombak tersebut telah berada di keraton, yang lebih panjang diberi nama Kèayè sè Nangghâ dijadikan sebagai senjata perang dan yang lebih pendek diberi nama Kèyaè sè Aluguro dijadikan sebagai penjaga keraton. Patih Prang Gulang sebenarnya bertapa di gua Ghunong Prao dan telah menjadi siluman yang dijuluki sebagai Kè Polèng.

Dalam hal menganalisis mitos Radhin Saghârâ, peneliti menggunakan teori struktural Levi-Strauss yang sama dengan penerapan kisah Oedipus. Mitos Radhin Saghârâ juga terdapat segmen-segmen atau peristiwa-peristiwa, dan setiap orang yang mengetahui mitos tersebut akan sependapat dengan hasil penelitian. Setiap segmen akan memperlihatkan relasi-relasi antar individu yang merupakan tokoh-tokoh dalam peristiwa. Relasi yang diutarakan akan menunjuk pada status-status pada individu tersebut.

Episode-episode dalam mitos Radhin Saghârâ terdapat miteme-miteme, sebagai berikut:

(1) Raja sangat murka karena putrinya diketahui hamil; 
(2) Raja menyuruh patihnya yang bernama Prang Gulang membawa putrinya ke hutan serta disuruh penggal lehernya;

(3) Patih Prang Gulang segera membawa Putri Bendara;

(4) Patih Prang Gulang membawa Sang Putri keluar dari hutan;

(5) Patih Prang Gulang segera menebang pohon,lalu dibuatnya rakit;

(6) Sang Putri diperintahkan naik ke atas rakit;

(7) Patih bersiul seolah-olah memanggil sesuatu dengan sebuah isyarat. Tak lama kemudian, lima ekor lumba-lumba datang dari tengah samudra;

(8) Sang Putri melahirkan putranya;

(9) Sang Putri menggendong Radhin Saghârâ dan berteduh di bawah pohon besar;

(10) Mereka merasa kagum melihat Raden Samudra yang aru saja dilahirkan, tapi sudah seperti anak yang berumur satu tahun;

(11) Kedatangan putra istimewa Sang Putri membuat pulau itu diberi nama Madura, yaitu Madunya Segara (samudra);

(12) Radhin Saghârâ tumbuh dewasa dan menjadi raja di pulau Madura;

(13) Radhin Saghârâ dengan mudah mencabut tombak yang tertancap pada mayat tersebut.;

(14) Patih Prang Gulang semenjak bertapa di gua Ghunong Prao telah menjadi siluman yang dijuluki sebagai Kè Polèng.

Berikut ini terdapat nama tokoh dengan nama-nama yang khas: (1) Sang Yang Tunggal, (2) Sang Yang Sumba, (3) Bendoro Ghung, (4) Patih Prang Gulang atau Kè, Polèng (meniru nama siluman penunggu candi Ijo supaya bisa menjadi siluman juga), (5) Radhin Saghârâ (yang berarti Raden Samodra), (6) Jhuko' Rajhâmèna (Jhuko' artinya ikan dan Rajhâmèna artinya raja nginang, menginang daun sirih).

Tokoh-tokoh tersebut sama-sama memiliki peran penting dalam kehidupan masyarakat pada masa itu. Peran yang akhirnya mempengaruhi sebagian keyakinan orang Madura pada masa sekarang. Berkenaan dengan tokoh yang bernama Patih Prang Gulang atau yang dijuluki sebagai Kè Polèng merupakan tokoh yang sangat beperan penting atas kejayaan Radhin Saghârâ. Dirunut dari cerita dalam mitos bahwa Radhin Saghârâ mempunyai paman yang menjadi raja di pulau Jawa yang bernama Sang Yang Sumba. Kerajaannya dijajah oleh negara asing, maka dari itu Patih Prang Gulang datang ke mimpi Radhin Saghârâ menyuruh untuk segera membantu pamannya.

Peran Kè Polèng dalam kehidupan selanjutnya bagi orang Madura khususnya di daerah Pamekasan nama Kè Polèng seakan-akan sebagai mantra. Sebagian orang Madura meyakini bahwa ketika ada orang sakit menyebut nama Kè Polèng sebanyak tiga kali akan menyembuhkan penyakitnya. Salah satu contoh, disebutkan bahwa ada orang tua yang percaya dengan menggunakan selembar daun sirih diolesi kapur kemudian menyebut nama Kè Polèng dapat menyembuhkan sakit mata. Berikut mantra yang diucapkan sekaligus menenmpelkan daun sirih tersebut pada sekeliling mata:

"Kè Polèng èntara jhâlân jhâu tape ta' nyabi kalambhi bân odheng kaangghuy pasalènan, mèla jârèya burung, burung, burung...."(Sadik,2005:20-21) . 
Artinya : "Kè Polèng hendak melakuakan perjalanan jauh tetapi tidak membawa baju dan menutup kepala untuk digunakan sebagai ganti, oleh karena itu gagal, gagal, gagal..."

Data tersebut merupakan mantra bagi orang Madura ketika hendak menyembuhkan sakit mata. Kata 'burung' yang artinya 'gagal' tersebut perumpamaan bahwa sakitnya tidak jadi menyerang tubuh kita. Hal tersebut merupakan keyakinan yang bisa saja dapat memberikan sugesti pada si sakit untuk segera sembuh karena percaya pada kesaktian Kè Polèng. Akan tetapi, tidak semua orang Madura mempercai bahwa Kè Polèng dan beberapa pengaruhnya dapat membuat orang sakit menjadi sembuh. Keyakinan atas usaha penyembuhan tersebut juga tidak dipercaya lagi oleh orang Madura pada masa sekarang karena dapat digolongkan dalam perbuatan syirik. Proses penyembuhan dengan menyebut nama selain Allah artinya menganggap bahwa Kè Polèng yang dapat menyembuhkan penyakit. Selain itu, kehadiran dokter juga telah menggeser keyakinan terebut karena menurut sebagain orang Madura hal tersebut tidak masuk di akal.

Hal lain mengenai kelebihan Kè Polèng disebutkan bahwa dia mempunyai pengaruh penting pada kehidupan Radhin Saghârâ. Bukti adanya peranan penting tersebut bahwa Radhin Saghârâ merasa sangat khawatir ketika melihat Patih Prang Gulang berperang dengan Jhuko' Rajhâmèna. Perang yang berakhir dengan tewasnya Jhuko' Rajhâmèna merupakan isyarat yang dikirimkan oleh patih melalui mimpi. Seakanakan nyata dalam mimpi itu terjadi badai yang sangat dasyat, pohon-pohon besar tumbang dan air laut meluap-luap. Peristiwa genting yang dialami oleh patih sengaja dikirimkan melalui mimpi atau bayangan kepada Radhin Saghârâ supaya ia dapat mengetahui patih dalam bahaya besar. Bentuk ketegangan dalam cerita mitos Radhin Saghârâ tercipta seperti layaknya cerita-cerita dalam karya sastra pada umumnya. Sarana ketegangan peristiwa dalam cerita disebut padahan (foreshadowing), yaitu penggambaran peristiwa yang akan terjadi.

Patih Prang Gulung menyebut dirinya Kè Polèng karena mengadaptasi nama dari siluman yang berada di candi Ijo di pulau Jawa. Alasannya adalah supaya dia dapat menjadi siluman. Adapun pakaian yang dipakai Patih Prang Gulang mengadaptasi dari pakaian Bima, bercorak hitam putih kotak-kotak. Hal tersebut terkait diperkirakan pada abad ke-15 sebagian orang di Madura dan Jawa mengagumi sosok Bima dalam cerita Bhatarayuda. Perihal yang dilakukan masyarakat Madura untuk menghormati Bima, terdapat adanya tempat-tempat yang dibangun tekait dengan Bima. Tempat- tempat tersebut yaitu Telapak Kaki Bima di daerah Pegunungan Dieng, pemandian Sungai Serayu disebut Bimo Lukar. Berkaitan dengan itu, di antariksa terdapat kumpulan bintang yaitu, Bima Sakti. Di Candi Ijo ada yang menjaga yaitu siluman yang bernama Kyai Poleng dan dikisahkan sering memakai pakaian layaknya Bima.

Dalam hubungan ini, terkait dengan perihal tersebut di Madura tepatnya patih dari Radhin Saghârâ yang bernama Kè Polèng juga memakai pakaian yang serupa dengan Kyai Poleng. Maka dari itu, batik yang coraknya kota-kotak hitam putih disebut Bâtè ' Polèng. Tidak hanya di Madura dan Jawa, disebutkan di Sumbawa ada juga kota yang 
bernama Bima karena menurut cerita kota tersebut yang mendirikan adalah Pandawa Lima (Sadik, 2005:18).

Adapun hal lain yang memiliki keterkaitan antara mitos Radhin Saghârâ dengan kehidupan masa kini adalah yang telah menjadi falsafah hidup orang Madura. Falsafah tersebut membebani orang Madura menjadi ramah, taat tunduk dan sopan, dalam Bahasa Madura adalah 'bhâpa' bhâbhu',ghuru lan rato', artinya 'bapak ibu, guru dan raja (pemerintah). Bagi orang Madura falsafah tersebut merupakan syarat untuk menjadi manusia yang baik dan selamat dunia akhirat. Perilaku budaya tersebut mengharuskan kita berbakti pada perintah bapak dan ibu, patuh pada guru yang baik, dan mematuhi peraturan dari pemerintah setempat. Bentuk kepatuhan tersebut tercermin dalam tindakan patuh dari patih terhadap perintah rajanya, seorang anak patuh pada perintah ayahandanya dan seorang murid yang patuh terhadap petunjuk gurunya.

Bentuk kepercayaan lain terhadap kehidupan nyata bagi orang Madura khususnya para nelayan yang tidak boleh menangkap lumba-lumba, membunuh, dan mengonsumsi sebagai makanan. Kepercayaan tersebut terkait dengan mitos yang terjadi pada kisah Radhin Saghârâ. Lumba-lumba bagi orang Madura tidak sekedar ikan besar yang tidak mampu ditangkap atau ditampung dengan jaring tradisional. Akan tetapi, Lumba-lumba dipercaya sebagai binatang yang mempunyai belas kasih untuk menolong manusia. Bentuk badannya yang besar, hitam dan menyeramkan menurut sebagian orang, lumbalumba adalah binatang yang dihormati dan dijaga kelestariannya oleh orang Madura. Apabila salah satu jaring nelayan tidak sengaja menangkap lumba-lumba, dirinya akan merasa mendapat rejeki dan dinaikkan derajatnya dalam kehidupan bermasyarakat. Lumba-lumba yang sudah tertangkap itu tidak akan dijual atau dikonumsi sendiri, tetapi dilepaskan lagi ke tengah laut dengan disaksikan banyak orang. Hal tersebut merupakan bentuk penghormatan pada lumba-lumba yang menurut cerita dalam mitos telah berjasa pada pendiri pulau Madura. Orang-orang yang ditolong lumba-lumba itu tidak lain adalah Sang Putri dan Radhin Saghârâ.

Oleh karena itu, bukan sesuatu hal yang berlebihan jika orang Madura masih meyakini bahwa lumba-lumba adalah ikan penyelamat manusia di tengah lautan. Sehubungan dengan hal itu, menurut beberapa riwayat dari cerita rakyat, jika para nelayan yang sedang melaut dan mengalami masalah di laut, lumba-lumba akan menolong mereka dengan cara menggiring perahunya ke pinggir pantai. Peristiwa tersebut bukan lagi merupakan kisah tahayyul yang tidak dapat dipercaya. Orang Madura juga mempercayai bahwa segala binatang laut yang tidak wajar ukuran tubuhnya, artinya sangat besar adalah perwujudan dari seorang pertapa. Sebuah kisah nyata yang pernah terjadi, di daerah pinggir laut Pamekasan. Di pagi harinya diketahui ada ikan Paus terdampar. Peristiwa langka tersebut membuat masyarakat pinggir pantai merasa risau dan bertanya-tanya. Berita terdamparnya paus menjadi berita luar biasa dan segera beredar isu-isu bahwa akan terjadi sesuatu yang berbahaya di sekitar daerah pesisir, bahkan hingga ke luar kota. Orang Madura percaya bahwa paus terdampar itu adalah perwujudan dari seorang pertapa yang telah mengalami kegagalan, sehingga dikutuk menjadi 'jhuko' rajâa' (ikan besar). 
Tingkat kepercayaan yang menurut beberapa orang di luar akal itu tetap menjadi bahan pembicaraan hangat di berbagai kalangan. Selanjutnya, selang beberapa hari masyarakat setempat akan mengadakan ritual di pesisir sekitar tempat kejadian. Ritual tersebut merupakan proses penghargaan terhadap paus dan pencegahan mala petaka. Berhubungan dengan hal itu, layaknya manusia paus yang terdampar tersebut akan didoakan untuk kemudian diangkat beramai-ramai dan dikuburkan di tempat yang tidak jauh dari pesisir pantai. Peristiwa langka tersebut akan menjadi sejarah dalam kehidupan masyarakat pesisir. Mereka akan mendokumentasikan ritual tersebut supaya suatu saat akan tetap menjadi kebanggan pada anak cucu. Sebuah kebanggan tersendiri bagi mereka karena pesisir pantainya telah disinggahi oleh 'jhuko' rajâ'. Selain di Pamekasan, masyarakat di Sumenep pernah juga mengawetkan 'jhuko' rajâ' (ikan paus) dan tulang belulangnya disimpan di dalam keraton Sumenep yang sampai sekarang masih dijaga keasliannya.

Tambahan pula, mengenai kepercayaan orang Madura yang berkaitan dengan mitos dan tahayyul. Bagi orang Madura beberapa binatang laut, di antaranya; kepiting, cumi-cumi, penyu, udang, kerang dan ikan pari dengan ukuran sangat besar akan dipercaya sebagai 'panjègena tasè' atau 'patoghuna tase'(penjaganya laut atau penunggu lautan). Sehubungan dengan itu, hal terlarang dalam dunia nelayan bahwa tidak diperbolehkan menangkap, menjual dan mengkonsumsi beberapa binatang tersebut. Diyakini bahwa akan ada akibat jika hal itu dilanggar, maka dari itu penjaga laut (panjègena tasè') yang lain akan murka dan membalas dendam dengan cara memuntahkan semua isi laut, artinya terjadi Tsunami.

Hal yang telah menjadi keyakian dan kepercayaan orang Madura akan sulit diubah dengan mudah. Beberapa kasus juga telah membuktikannya, bahwa sistem keyakianan tersebut akan tetap terjaga meskipun sisi modernitas telah mewarnai pulau Madura. Proses keyakinan tersebut akan tetap bertahan karena karakter orang Madura begitu keras untuk diubah menjadi orang yang di luar sepengetahuannya. Kepercayaan dan keyakinan yang berbau mistik tersebut tetap terjaga di kalangan nelayan. Hal itu juga disebabkan karena mereka telah membedakan atau memilah-milah antara prinsip komunitas dan prinsip pribadi. Uraiannya, prinsip komunal tersebut berupa keyakinan yang berhubungan dengan interaksi sosial jika kita melanggarnya. Beberapa sanksi dari masyarakat tidak akan bisa dihindarkan jika kita melanggarnya. Salah satu sanksi yang sampai sekarang menjadi hal biasa adalah cemooh dan pengucilan terhadap pelanggar norma. Sanksi tersebut telah disepakati sebagai sanksi pertama dalam kehidupan bermasyarakat. Prinsip pribadi adalah prinsip yang hanya melibatkan diri sendiri sebagai manusia yang hidup di bumi. Sanksi ini akan mempengaruhi kejiwaan seseorang setalh melakukan tindakan yang tidak diperbolehkan oleh kalangan masyarakat atas tempat tinggalnya.

Adapun yang berhubungan dengan prinsip pribadi dan terkait dengan prinsip komunal dalam mitos adalah ketika Sang Yang Tunggal murka mengetahui putrinya hamil tanpa suami. Di dalam cerita juga tidak disebutkan bahwa kenapa tiba-tiba Sang Putri hamil dan dengan siapa hamil. Dalam konteks ini, ada mitos yang mirip dengan mitos Radhin Saghârâ yaitu mitos Joko Tole. Tokoh Joko Tole dan adikknya Agus Wedi 
memiliki kemiripan kisah dengan Radhin Saghârâ. Mereka sama-sama merupakan cucu dari seorang raja dan putra dari seorang putri raja. Akan tetapi, jika dalam cerita mitos Joko Tole ayahnya diketahui adalah seorang pertapa yang konon jauh berada di seberang pulau, yaitu pulau Sapudi atau Podây. Walaupun demikian, ibu dari Joko Tole hamil karena dia bermimpi didatangi oleh pertapa yang bernama Adi Podây sewaktu bertapa di gua Pajhudhân.

Peristiwa gaib yang dialami oleh ibunda Joko Tole menjadikan Potrê Konêng hamil tanpa suami dalam ikatan pernikahan dan pesta rakyat layaknya pesta pernikahan putri-putri raja. Akhirnya, supaya ayahandanya tidak murka Potrê Konêng melahirkan diam-diam kemudian membuang bayinya di bawah pohon besar di dalam hutan. Bayi mungil tersebut ditemukan oleh seorang pandai besi yang sedang mengembala sapi dan diberi nama Joko Tole. Masa kecil Joko Tole hidup sederhana dan menjadi anak seorang pandai besi sampai akhirnya ia pergi ke kerajaan Majapahit.

Mitos Radhin Saghârâ justru memiliki alur yang lebih pendak dan singkat daripada mitos Joko Tole. Ada perbedaan peristiwa dalam kedua mitos tersebut, salah satunya pada saat raja mengetahui putrinya hamil tanpa suami. Di dalam mitos Radhin Saghârâ Sang Yang Tunggal selaku seorang raja harusnya menjadi panutan dan teladan bagi rakyatnya. Kharisma dan wibawa yang dibentuk selama bertahun-tahun dirusak oleh putrinya sendiri. Hal tersebut yang akhirnya menguji kekuatan prinsip raja, antara rasa sayang terhadap putrinya atau sebuah kebijakan atas pelanggaran yang dilakukan, meskipun terjadi pada putrinya sendiri. Sang Yang Tunggal murka terhadap pelanggaran yang dilakukan putrid kandungnya sendiri, sehingga mengusir dan memerintahkan putrinya untuk dipenggal. Akan tetapi, lain halnya dengan raja di dalam mitos Joko Tole, ia tidak mengusir putrinya dari kerjaaan. Hal tersebut disebabkan karena putri tidak memberitahukan perihal kehamilannya kepada ayahandanya. Pelanggaran tetap pelanggaran yang tidak dapat ditoleransi meskipun yang melakukannya adalah orang terdekat. Kebijakan tersebut pada akhirnya akan menjadi sebuah panutan bagi rakyatnya. Prinsip hidup tersebut yang dianut dan dilakukan oleh kakek Radhin Saghârâ selaku raja di sebuah kerajaan.

\subsection{Bahasa pada Mitos Radhin Saghârâ}

Bahasa adalah sebuah media, alat, atau sarana untuk komunikasi, untuk menyampaikan pesan-pesan dari satu individu ke individu lain, dari kelompok satu ke kelompok yang lain. Berikut data yang terdapat pada mitos Radhin Saghârâ.

'Mara Patè la lakonè apa sè pakonaghi rama rato ka bâ'na, sèngko' la pasra. Bilâ bhâi manossa reya bisa mate, satèya otabâ lagghuna, bâriyè kèya sèngko'"'(Sadik,2005:12)

"Duh, ghustè kaulâ ta' bisa ngalampa'aghi pakonna rato sè sèttong panèka.." (Sadik,2005:13)

Artinya : "Silakan Patih kerjakan saja apa yang diperintahkan ayahanda padamu. Saya sudah pasrah. Kapan saja manusia bisa mati, sekarang atau besok, begitu juga dengan saya" 
"Duh, gusti saya tak bisa mengerjakan perintah raja yang satu ini."

Data tersebut menunjukkan adanya bahasa yang digunakan dalam cerita. Bahasa yang digunakan merupakan media atau alat untuk berkonikasi dan menyampaikan pesan antara individu dengan individu yang laninya. Di dalam data ada bentuk komunikasi antara Sang Putri dengan Patih Prang Gulang. Sang Putri menangis sesenggukan hingga matanya sembab, dia kemudian sadar bahwa manusia akan mati juga nantinya. Sang Putri berserah diri apabila Patih Prang Gulang akan memenggal kepalanya. Akan tetapi, Patihnya tidak tega memenggal kepala Sang Putri.

Bahasa yang digunakan dalam mitos tersebut merupakan bahasa yang memiliki tinggatan tinggi, yaitu èngghi bunten atau kromo inggil dalam bahasa Jawa. Hal yang mendasari karena latar yang digunakan adalah kerajaan karena ada bahasa khusus yang digunakan terhadap raja dan ratu, kepada orang yang lebih tua dan lebih tinggi derajatnya. Bahasa èngghi bunten tersebut tidak jauh beda dengan kromo inggil karena beberapa bahasa Madura merupakan hasil serapan dan adaptasi dari bahasa Jawa. Data di merupakan bahasa yang digunakan oleh Patih Prang Gulang selaku bawahan dari putri raja Sang Yang Tunggal. Oleh karena itu, bahasa yang digunakan adalah bahasa èngghi bunten. Kalimat berikut yaitu 'Duh, ghustè kaulâ ta' bisa ngalampa'aghi pakonna rato sè sèttong panèka', yang berarti bahasa yang digunakan oleh seorang bawahan terhadap atasannya, pada raja, ratu , pangeran dan putri raja.

Data berikut merupakan gaya bahasa yang digunakan oleh A. Sulaiman Sadik dalam cerita mitosnya. Bahasa dalam data berikut ini merupakan bahasa yang menggunakan bahasa èngghi bunten:

É polo jhảbả bảdả rato anyama Sang Yang Tunggal. Rato bhuru ghảdhuwản pottra kaduwả, lakẻ' binẻ'. Pottra lakẻna anyama Sang Yang Sumba, sẻ binẻ' anyama Bendoro Ghung. É sẻttong bảkto rato sanget dhukana amarghả pottrẻna étemmo bhubhut, m€lana dhuka sabảb potrẻna kasbbhut ghi' ta' araka. dảri seddhina rato lajhu makon papatẻna sẻ anyama Prang Gulang ngébả pottrẻna jảrẻya ka alasm sẻrta épakon kettok cẻtakka, bản cẻtakka jảréya pakon kẻbả molẻ ka karaton mẻnangka bhuktẻ jhả’ pottrẻna jảrẻya ella matẻ. (Sadik, 2005: 12)

Artinya : Di pulau Jawa ada raja yang bernama Sang Yang Tunggal. Raja baru saja memiliki dua putra, laki-laki dan perempuan. Putranya bernama Sang Yang Sumba, putrinya bernama Bendoro Ghung. Di suatu waktu raja sangat murka karena putrinya diketahui hamil, kemurkaannya disebabkan karena putrinya belum bersuami. Rasa sedihnya membuat raja menyuruh patihnya yang bernama Prang Gulang membawa putrinya ke hutan serta disuruh penggal lehernya, dan kepalanya dianjurkan untuk dibawa pulang ke keraton sebagai bukti bahwa putrinya telah mati.

\section{Kesimpulan}

Teori strukturalisme Levi-Strauss digunakan sebagai model analisis untuk memaknai mitos Radhin Sahgârâ. Dengan demikian atas penggunaan teori ini, ada dua 
tahap untuk menganalisis struktur mitos tersebut. Tahap pertama, untuk menemukan mytheme-mytheme dalam mitos. Pada tahap kedua, memperlihatkan beberapa tokohtokoh yang memiliki peran penting dalam kehidupan masyarakat pada masa itu dan mempengaruhi sebagian keyakinan orang Madura pada masa sekarang. Peran Kè Polèng bagi orang Madura khususnya di daerah Pamekasan adalah seakan-akan sebagai mantra untuk media penyembuhan secara tradisional. Kè Polèng diyakini sebagai tokoh yang mengadaptasi tokoh Bima, sehingga para pengrajin batik di Madura menyebut batik dengan corak kota-kotak hitam putih sebagai Bâtè' Polèng. Bentuk kepercayaan lainnya terkait dengan mitos Radhin Saghârâ, bagi para nelayan di Madura tidak boleh menangkap lumba-lumba dan membunuhnya. Kepercayaan yang masih dijalankan oleh orang Madura merupakan bentuk dari penghormatan yang sakral terhadap mitos- mitos yang ada di Madura. Orang Madura memiliki kepercayaan dan keyakinan terhadap daya mistik atau gaib secara berlebihan. Hal itu terjadi karena orang Madura mencintai alam sekitar yang mereka tempati, bahwa alam akan murka jika manusia berulah dan melanggar pantangan.

\section{Daftar Pustaka}

Putra, Heddy Shri Ahimsa. 2009. Struktural Levi-Strauss Mitos dan Karya Sastra. Yogyakarta: KEPEL PRESS.

Putra, Heddy Shri Ahimsa. 2008. Paradigma dan Revolusillmu dalam Antropologi Budaya. Yogyakarta: KEPEL PRESS.

Pradopo, Rachmat Djoko. 2003. Prinsip-Prinsip Kritik Sastra. Yogyakarta: Gadjah Mada University Press.

Sadik, A.Sulaima.2005. Sangkolan. Bina Pustaka Jaya: Pamekasan.

Teeuw, A. 2003. Sastera dan Ilmu Sastera. Jakarta: Pustaka Jaya.

Tim Penyusun Kamus Pusat Pembinaan dan Pengembangan Bahasa.2001. Kamus Besar Bahasa Indonesia. Jakarta: Balai Pustaka. 